\title{
Some topographical observations on fibrinolysis
}

\author{
A. S. TODD \\ From the Department of Pathology, Queen's College, Dundee
}

The previous papers have described how the fibrinolytic activity of plasma and cerebrospinal fluid may be measured. However, at the site of fibrin formation in the body the fibrinolytic process may also depend on the nature of the fibrin itself and on the enzyme activity of the nearby tissues.

\section{THE TOPOGRAPHY OF FIBRINOLYTIC \\ ACTIVITY IN NORMAL TISSUES}

The distribution of fibrinolytic activity in tissues may be studied by the technique of fibrinolysis autography (Todd, 1958, 1959, 1960). This is a histological method in which a section of fresh tissue is incubated in contact with a thin layer of

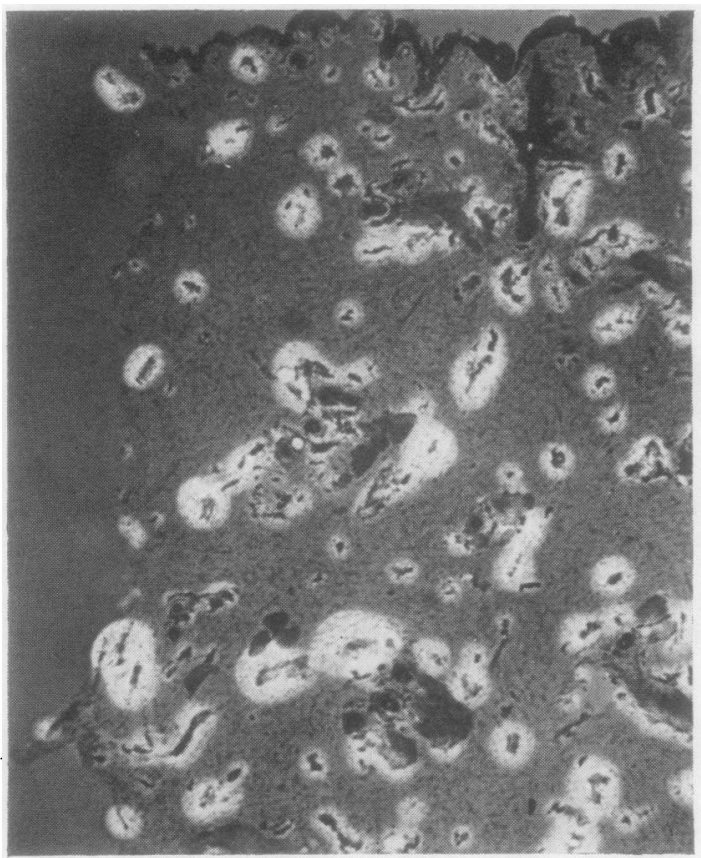

FIG. 1 bovine fibrin. During incubation discrete zones of $\vec{A}$ digestion appear in the fibrin, related presumably to concentrations of fibrinolytic enzymes in the over- $\overline{\widehat{O}}$ lying tissue. If the fibrin and tissue, still in contact, be fixed, stained and mounted for microscopy, the $-\overrightarrow{ }$ areas of digestion are seen as pale gaps in a uniform ${ }_{\omega}^{\omega}$ background of stained fibrin and can be correlated topographically with the structures in the overlying ${ }_{0}$ section (Fig. 1). The digestion must be due to plasminogen activator in the tissues since no $\frac{\vec{z}}{3}$ fibrinolytic zones are seen if the fibrin is previously rendered plasminogen-free by heating according to $\vec{\oplus}$ the method of Lassen (1953).

This technique reveals that most of the plasminogen activator in tissues is concentrated in the? 

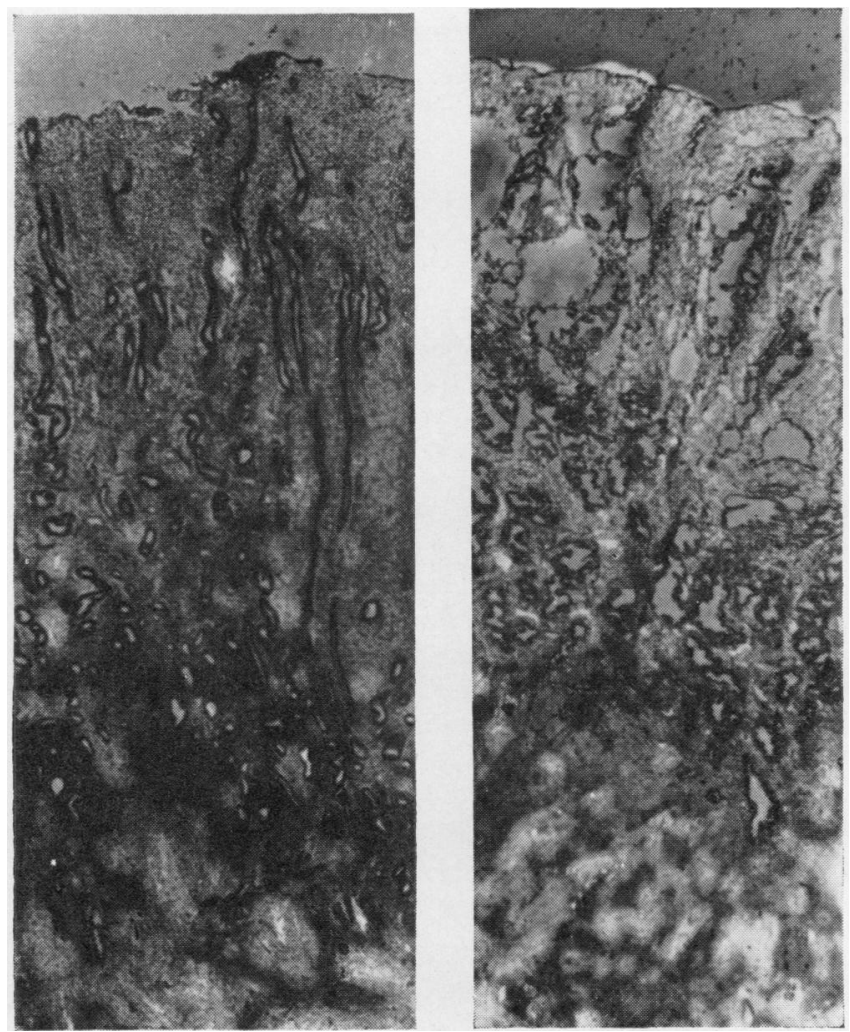

FIG. 3. Fibrinolysis autographs of (a) proliferative endometrium $(\times 14 \cdot 5)$ showing focal fibrinolytic activity and (b) late secretory endometrium $(\times 9)$ showing diffuse superficial fibrinolytic activity. Note the consistently high activity of the myometrium (below).

FIG. 4. Fibrinolysis autograph of cervix uteri $(\times 50)$ showing a focus of fibrinolytic activity in the squamous epithelium.

FIG. 5. Unstained fibrinolysis autograph of inflamed rat cremaster labelled with colloidal silver $(\times 85)$. Note the black silver granules in the wall of one of the fibrinolytic vessels.
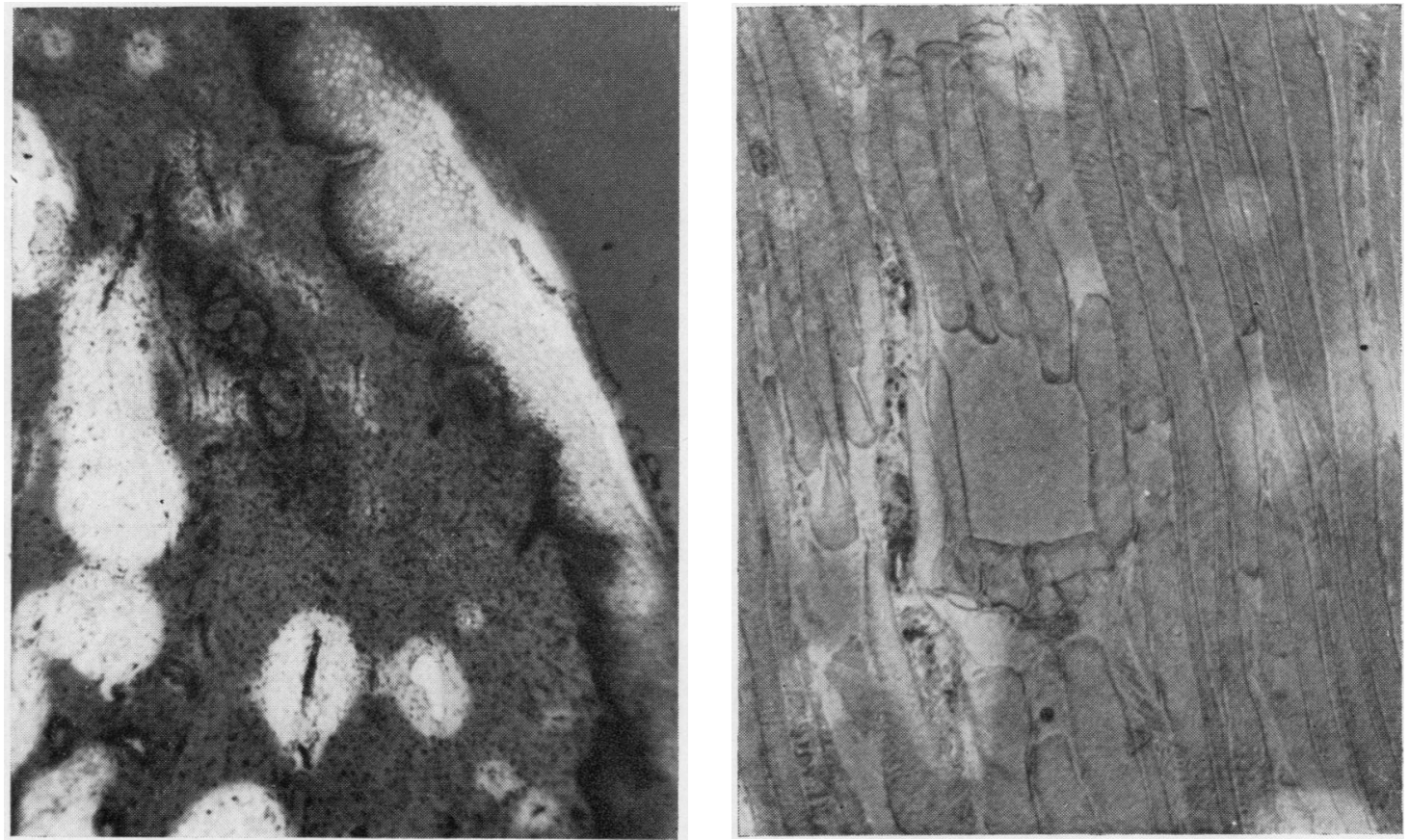

FIG. 4

FIG. 5 
epithelium of veins (Fig. 2). Arterial endothelium usually contains little or no activator and serosal cells none, but if streptokinase is added to the fibrin layer all three types of cell show increased activity, suggesting that they contain pro-activator (Astrup, 1956). Thus in veins the fibrinolytic system is at the ready while in arteries and serous linings it has to be primed by some unknown stimulus.

\section{TOPOGRAPHY OF FIBRINOLYTIC ACTIVITY IN RELATION TO EXUDATION}

The possibility of a relation between fibrinolysis and exudative conditions was suggested by observations on endometrium prompted by the work of Whitehouse (1914) and Albrechtsen (1956). Whitehouse showed that the blood of the menstrual discharge is incoagulable because the clot formed within the uterine cavity is reliquefied by endometrial enzymes before it escapes from the uterus. Albrechtsen showed that the fibrinolytic activity of endometrium is cyclical and partly under hormonal control. Fibrinolysis autographs of endometrium have now demonstrated that the activity in the proliferative phase is focal and related to blood vessels in the basal layer (Fig. 3a), but when the bleeding phase approaches, then diffuse activity appears in the superficial layers (Fig. 3b) and becomes maximal coincidentally with the appearance of interstitial fluid and cellular exudate. This suggested that fibrinolysis might be related to the exudative process.

A connexion between fibrinolytic activity of tissues and infective exudation was suggested by the finding of foci of plasminogen activator in squamous epithelium of skin and cervix uteri. The foci occur in squamous epithelium either overlying areas of round cell infiltration in chronic cervicitis (Fig. 4) or adjacent to necrotic and infected neoplasms. In these preparations it looks as if plasminogen activator had been released from the injured tissues to stagnate in spongy intercellular spaces of the epithelium. Thus it may be that in man, exudation, however elicited, is accompanied by increased fibrinolytic activity of abnormal distribution.

Experiments were carried out in rats to test this hypothesis. Exudation was caused by the injection of xylene, histamine, or 5-hydroxytryptamine into the scrotal skin (Majno, Palade, and Schoefl, 1961). Vascular leakiness was demonstrated by injecting silver colloid intravenously immediately before the local inflammatory stimulus. Wherever the blood vessels became leaky, silver particles escaped from the blood stream and were trapped between the endothelium and basement membrane thus labelling the vessel walls. When autographs were made from inflamed tissues labelled in this way fibrinolysis was seen around the vessels showing silver deposition, $\stackrel{0}{\overrightarrow{0}}$ that is, the veins and venules (Fig. 5), but the amount . and distribution of this activity seemed the same as $\overrightarrow{\vec{S}}$ that of normal tissues.

TOPOGRAPHY OF FIBRINOLYSIS IN THROMBI AND FIBRINOUS EXUDATE

To determine whether naturally formed fibrin may contain components of the fibrinolytic system $\vec{\circ}$ (plasmin or plasminogen activator) pulmonary emboli from two cases and lung showing fibrinous $\vec{\omega}$ pleural exudate were examined by the autograph? technique. After incubation for one hour at $37^{\circ} \mathrm{C}$.? the fibrin film showed no areas of lysis but if $\vec{v}$ incubation were continued for a further hour, much $\omega$ digestion of the substrate occurred in relation to dense strands of fibrin in the thrombus, particularly those at the surface (Fig. 6). It is unlikely that this 5 activity could have come from leucocytes since it is $\overrightarrow{-}$ related to cell-free parts of the thrombus. A possible explanation is that plasminogen activator had been adsorbed from the circulating blood or from the $\bar{\emptyset}$ adjacent endothelium. This adsorption idea was? tested using artificial thrombi made by the methodo

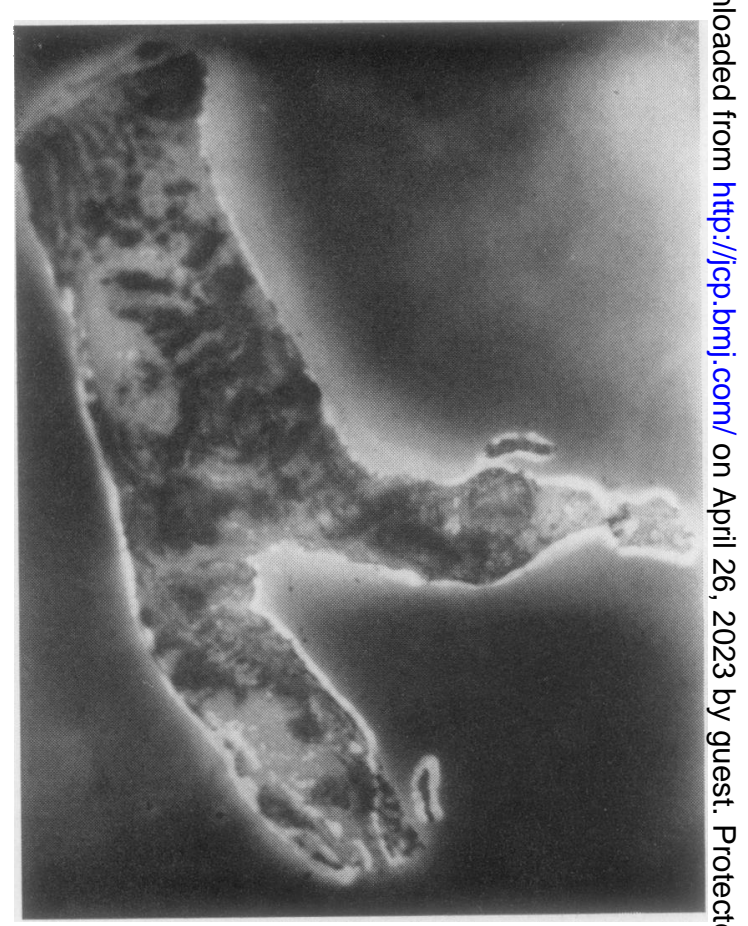

FIG. 6. Fibrinolysis autograph of part of a pulmonary embolus $(\times 5)$ showing fibrinolytic activity especially ato the surface. 
of Chandler (1958) modified by Poole (1959). In this technique blood is coagulated in a rotating loop of plastic tubing; it forms a laminated body with the structure of a natural thrombus, the bulk of the blood remaining fluid. Such 'thrombus' shows no fibrinolytic activity when tested by the autograph method. On the other hand if streptokinase, a plasminogen activator, is added to the rotating system after coagulation has occurred, the thrombi then show fibrinolytic activity of the same distribution as that seen in pulmonary emboli. The experimental model, therefore, seems to confirm the suggestion that thrombi may adsorb plasminogen activator. In the case of the pleural exudate the fibrinolytic activity was more diffuse so that an origin from the many leucocytes present could not be excluded.

\section{SUMMARY}

Fibrinolytic activity in human tissues is due to plasminogen activator concentrated in venous endothelium. Arterial endothelium and serosal cells contain proactivator. Plasminogen activator may also be found in the superficial endometrium, at the time of menstrual shedding, in squamous epithelium adjacent to areas of inflammation, and in thrombi and fibrinous pleural exudates.

I gratefully acknowledge the help of Professor A. C. Lendrum in the preparation of the manuscript; of Miss A. Christie in making the experiments; and of the Secretary of State for Scotland in making a grant of money.

\section{REFERENCES}

Albrechtsen, O. K. (1956). Acta endocr. (Kbh.), 23, 207.

Astrup, T. (1956). Blood, 11, 781.

Chandler, A. B. (1958). Lab. Invest., 7, 110.

Lassen, M. (1953). Acta physiol. scand., 27, 371.

Majno, G., Palade, G. E., and Schoefl, G. I. (1961). J. Biophys. biochem. Cytol., 11, 607.

Poole, J. C. F. (1959). Quart. J. exp. Physiol., 44, 377.

Todd, A. S. (1958). Nature (Lond.), 181, 495.

- (1959). J. Path. Bact., 78, 281.

- (1960). In Thrombosis and Anticoagulant Therapy, edited by W. Walker, p. 25. University of St. Andrews.

Whitehouse, H. B. (1914). Lancet, 1, 877.

DR. McNICOL asked if Dr. Todd had used E.A.C.A. in his experiments.

DR. TODD replied that he had, but that it was not possible to use sufficient E.A.C.A. to produce inhibition in his experiments in vitro.

In a reply to a question by DR. EDWARD, he said that if E.A.C.A. was incorporated in the fibrin it would inhibit fibrinolysis. 